\title{
Transition metal doped cryptomelane-type manganese oxide catalysts for ozone decomposition
}

\author{
Jinzhu Ma ${ }^{\mathrm{a}, \mathrm{b}, \mathrm{c}}$, Caixia Wang ${ }^{\mathrm{a}}$, Hong $\mathrm{He}^{\mathrm{a}, \mathrm{b}, \mathrm{c}, *}$ \\ a State Key Joint Laboratory of Environment Simulation and Pollution Control, Research Center for Eco-Environmental Sciences, Chinese Academy of \\ Sciences, Beijing 100085, China \\ ${ }^{\mathrm{b}}$ Center for Excellence in Regional Atmospheric Environment, Institute of Urban Environment, Chinese Academy of Sciences, Xiamen 361021, China \\ c University of Chinese Academy of Sciences, Beijing 100049, China
}

\section{A R T I C L E I N F O}

\section{Article history:}

Received 25 May 2016

Received in revised form 1 August 2016

Accepted 22 August 2016

Available online 22 August 2016

\section{Keywords:}

Octahedral molecular sieve (OMS)

Manganese dioxide

Cryptomelane

Transition metal-doped $\mathrm{MnO}_{2}$

Ozone decomposition

\begin{abstract}
A B S T R A C T
Transition metal (Cerium, Cobalt, and Iron) doped cryptomelane-type manganese oxide (M-OMS-2) catalysts have been successfully synthesized and characterized. The different metal-ion-doped K-OMS-2 catalysts showed distinct differences in their ozone decomposition activity. Cerium-doped OMS-2 materials showed ozone conversion of $90 \%$ under $\mathrm{RH}=90 \%$ and space velocity of $600,000 \mathrm{~h}^{-1}$. X-ray diffraction (XRD), thermogravimetric analysis (TGA), and X-ray photoelectron spectroscopy (XPS) data suggested that the as-synthesized M-OMS-2 materials were all crystalline with no segregated metal oxide impurities. ICP-OES and XAFS results confirmed that $\mathrm{Co}^{3+}$ and $\mathrm{Fe}^{3+}$ replace $\mathrm{Mn}^{3+}$ in the cryptomelane structure and $\mathrm{Ce}^{4+}$ mainly replaces the $\mathrm{K}^{+}$in the tunnel and partially replaces the $\mathrm{Mn}^{4+}$ in the framework of the cryptomelane structure. Because of the differences in the substitution sites and the ionic radius of dopants, the morphologies of the catalysts were different. The $\mathrm{Mn}^{3+}$ content and number of surface defects play a key role during the decomposition of ozone. Ce-OMS-2 is a promising catalyst for purifying waste gases containing ozone under high-humidity conditions.
\end{abstract}

(ㄷ) 2016 Elsevier B.V. All rights reserved.

\section{Introduction}

As an effective oxidant, ozone is widely used in purification of waste and natural water, as well as polluted air [1-3]. Nevertheless, the off gas from the oxidation process still contains some amount of ozone that is often far beyond the admissible levels. High concentrations of ozone can cause health problems to human beings including neurological diseases, increased frequency of respiratory symptoms and reduced immune system function, and its release into the environment must be avoided [4]. According to the U.S. Environmental Protection Agency (U.S. EPA) regulations, the allowable exposure to ozone in terms of eight-hour average concentration is $80 \mathrm{ppb}$, and the Chinese 'indoor air quality standards' (GB/T 18883-2002) require that the indoor ozone concentration should not exceed $0.07 \mathrm{ppm}$ [5]. Therefore, research on the decomposition of ozone is important from the point view of environmental protection and public health.

\footnotetext{
* Corresponding author at: State Key Joint Laboratory of Environment Simulation and Pollution Control, Research Center for Eco-Environmental Sciences, Chinese Academy of Sciences, Beijing, 100085, China.

E-mail address: honghe@rcees.ac.cn (H. He).
}

Because it is safe, economical and efficient, catalytic decomposition is the most effective method for purifying waste gases containing ozone. Among the developed catalysts, manganese oxide catalysts are known to be among the most effective and economical for ozone decomposition [6]. Compared with pure manganese oxides, mixed manganese-metal oxides seem to have better activity due to the interaction of the different metals [7]. However, at high relative humidity $(\mathrm{RH})$, the activity of Mn oxidebased catalysts is diminished. Water vapor has a severe influence on catalytic performance in ozone decomposition, with $\mathrm{H}_{2} \mathrm{O}$ molecules competing with ozone for adsorption on the oxide surface, leading to a decrease in catalytic activity [8]. The addition of Pd or Ag can help the catalysts resist water and slow down the reduction in activity due to humidity $[9,10]$, but the high cost of noble metals limits their widespread application.

Manganese oxide octahedral molecular sieve (OMS) materials, especially the cryptomelane-type OMS material OMS-2, are environmentally benign and relatively cheap, and have found a wide range of applications in the field of catalysis [11-14]. In our previous study, an OMS-2 catalyst synthesized using $\mathrm{MnAc}_{2}$ as $\mathrm{Mn}^{2+}$ precursor showed the best catalytic activity for ozone decomposition $(\sim 75 \%)$ at $\mathrm{RH}=90 \%$ compared to catalysts made with other precursors, and the increased surface area and higher amount of $\mathrm{Mn}^{3+}$ 
were the main factors contributing to the excellent performance of OMS-2-Ac [15]. It also has been reported that the structure, morphology, valence of manganese species, and lattice parameters of OMS-2 can be tuned through single or/and multiple substitution of tunnel $\mathrm{K}^{+}$ions and framework Mn ions by a variety of metal ions, such as $\mathrm{Cu}^{2+}, \mathrm{Zn}^{2+}, \mathrm{Ni}^{2+}, \mathrm{Co}^{2+}, \mathrm{Fe}^{3+}, \mathrm{Ti}^{4+}, \mathrm{Ce}^{4+}, \mathrm{W}^{6+}, \mathrm{V}^{5+}$ and $\mathrm{Nb}^{5+}[11,16-28]$. For example, Hu et al. [16] found that transition metal-modified OMS-2 catalysts had high surface area, more oxygen vacancies and more surface-bonded $\mathrm{OH}$ groups compared with undoped OMS-2, which increased the catalytic removal of aqueous phenol. Tang et al. [20] indicated that the catalytic activity toward CO oxidation at ambient temperature for Ti-OMS-2 showed a correlation with the surface area, the morphology and the titanium content. Wang et al. [29] found that the morphology of $\mathrm{MnO}_{x}$ play a key role for the decomposition of ozone on $\mathrm{MnO}_{x} / \mathrm{AC}$ catalysts. However, to the best of our knowledge, the use of transition metal doped cryptomelane-type manganese oxide (M-OMS-2) materials for ozone decomposition has not been reported. In this study, a series of metal-modified (Cerium, Cobalt, and Iron) OMS-2 materials were synthesized and tested for ozone decomposition under high relative humidity, and the relationship between the structure and the catalytic performance as well as the effect of additional metals was explored.

\section{Experimental}

\subsection{Preparation of catalysts}

The OMS-2 materials were prepared by reaction between $\mathrm{Mn}^{2+}$ and potassium permanganate via a hydrothermal method, which was described in detail in our previous work [15]. During the synthesis of transition metal doped OMS-2, the nominal weight ratio of transition metal ( $\mathrm{Ce}, \mathrm{Co}$ and $\mathrm{Fe}$ ) to Mn for every sample was controlled at 0.125 . Cerium-modified OMS-2 catalysts (CeOMS-2) were prepared via a one-step hydrothermal synthesis. The detailed procedure is as follows: $3.668 \mathrm{~g}$ of $\mathrm{MnAc}_{2} \cdot 4 \mathrm{H}_{2} \mathrm{O}$ and $0.623 \mathrm{~g}$ $\mathrm{Ce}\left(\mathrm{NO}_{3}\right)_{3} \cdot 4 \mathrm{H}_{2} \mathrm{O}$ were dissolved in deionized water under stirring. $2.5 \mathrm{~mL}$ glacial acetic acid was then added in order to form an acidic environment. Next a solution of $2.168 \mathrm{~g} \mathrm{KMnO}_{4}$ in deionized water was added to the above mixture under stirring. Finally, the mixed solution was maintained at $100^{\circ} \mathrm{C}$ for $24 \mathrm{~h}$ in a Teflon-lined autoclave and then cooled to room temperature. The resulting black slurry was centrifuged, washed by deionized water and dried at $100{ }^{\circ} \mathrm{C}$ overnight. The synthesis of Co-OMS- 2 and Fe-OMS- 2 followed the above procedure with the same transition metal to Mn mass ratio. The $\alpha-\mathrm{MnO}_{2}$ catalysts (confirmed by XRD in Fig. S1) were prepared for reference by a hydrothermal method similar with our previous work [30].

\subsection{Catalyst characterization}

The crystalline structure of the catalysts was determined by a powder X-ray diffractometer (XRD; X'Pert PRO, PANalytical, Netherlands) using $\mathrm{Cu} \mathrm{K} \alpha(\lambda=0.15406 \mathrm{~nm})$ radiation at $40 \mathrm{kV}$ and $40 \mathrm{~mA}$ with the step size of $0.065^{\circ}(2 \theta)$.

Thermal analysis was determined on TGA/DSC1 STAR ${ }^{\mathrm{e}}$ system (METTLER TOLEDO) at a heating rate of $10^{\circ} \mathrm{C} / \mathrm{min}$ from $30^{\circ} \mathrm{C}$ to $900{ }^{\circ} \mathrm{C}$ under $50 \mathrm{~mL} / \mathrm{min}$ flowing nitrogen.

For the morphology study, the OMS-2 materials were investigated using a SU8000 field emission scanning electron microscope (FESEM), and the accelerating voltage was $3000 \mathrm{~V}$. Before FE-SEM measurements, the samples were prepared by depositing the powder on a conductive tape using N2 vertical purging.

A physisorption analyzer (Autosorb-1C-TCD, Quantachrome) was used to measure the surface area and pore structure (vol- ume and size) of the catalysts by $\mathrm{N}_{2}$ adsorption-desorption at $77 \mathrm{~K}$. All samples were degassed at $90^{\circ} \mathrm{C}$ for $12 \mathrm{~h}$ to remove the physisorbed moisture before the $\mathrm{N}_{2}$ adsorption. The surface area $\left(\mathrm{S}_{\mathrm{BET}}\right)$ was determined by applying the Brunauer-Emmett-Teller (BET) method to the adsorption isotherm in the partial pressure range of $0.05-0.35$. The pore volume $\left(\mathrm{V}_{\mathrm{BJH}}\right)$ and the pore diameter $\left(D_{\mathrm{BJH}}\right)$ were determined by the Barrett-Joyner-Halenda $(\mathrm{BJH})$ equation from the desorption isotherm.

The X-ray absorption near edge structure (XANES) and extended $\mathrm{X}$-ray absorption fine structure (EXAFS) of the Mn-K edge in the OMS- 2 catalysts were measured in transmission mode on the 1W1 B beam line, Beijing Synchrotron Radiation Facility and BL14W1 beamline, Shanghai Synchrotron Radiation Facility. Data evaluation was carried out with IFEFFIT 1.2.11. XANES data were normalized by edge height and then the first-order derivatives were taken to compare the variation of absorption edge energies. EXAFS oscillation $\chi(k)$ was extracted using spline smoothing with a CookSayers criterion, and the filtered $k^{3}$-weighted $\chi(k)$ was Fourier transformed into $\mathrm{R}$ space in the $k$ range of $3-12 \AA^{-1}$. In the curvefitting step, the backscattering amplitude and phase shift were calculated using FEFF8.4 code.

$\mathrm{X}$-ray photoelectron spectroscopy (XPS) results of the catalysts were recorded on a Scanning X-ray Microprobe (AXIS Ultra, Kratos Analytical, Inc.). Binding energy was calibrated with C1s $=284.8 \mathrm{eV}$.

Elemental analysis was conducted using an inductively coupled plasma emission spectrometer (ICP-OES). All samples were dissolved using strong acid solution before being tested. The calibration solution was prepared using pure materials. The average of three atomic emission lines was used to determine the metal contents in the catalysts.

\subsection{Catalyst activity for ozone decomposition}

The ozone decomposition texts were conducted in a fixed bed continuous flow quartz reactor $\left(4 \mathrm{~mm}\right.$ i.d.) at temperature $30^{\circ} \mathrm{C}$, and the space velocity in all experiments was $600,000 \mathrm{~h}^{-1}$. About $0.1 \mathrm{~g}$ catalysts was used for each experiment. The gas flow passing through the reactor was $1000 \mathrm{~mL} / \mathrm{min}$, with $800 \mathrm{~mL} / \mathrm{min} \mathrm{N}_{2}$ and $200 \mathrm{~mL} / \mathrm{min} \mathrm{O}_{2}$. The relative humidity ( $\mathrm{RH}=45 \%$ and $90 \%$ ) of the feed gas stream was maintained by change the gas flow through a bubbler, which was with circulated water at a constant temperature $\left(25^{\circ} \mathrm{C}\right)$ using a circulator. The relative humidity was measured using humidity equipment (HMP110, vaisala oyj). The concentration of inlet ozone, which was generated by low-pressure ultraviolet lamps, was $40 \pm 2 \mathrm{ppm}$. Inlet and outlet ozone concentrations were monitored online with an ozone monitor (Model 202, 2 B Technologies). In order to verify uniformity throughout the experiments, the temperature and pressure drop were also recorded at the same time. The activity of the catalyst was calculated on the basis of the following equation:

$\mathrm{O}_{3}$ conversion $=\frac{\mathrm{C}_{\text {in }}-\mathrm{C}_{\text {out }}}{\mathrm{C}_{\text {in }}} \times 100 \%$

where $C_{\text {in }}$ and $C_{\text {out }}$ are inlet and outlet concentration of ozone respectively. The reproducibility of the catalyst tests were done for Ce-OMS-2 and the data shows that the error bar is less than $3.6 \%$, which confirms the validity of our data.

\section{Results and discussion}

\subsection{Ozone decomposition performance}

The decomposition of ozone was negligible when control experiments were performed without catalysts (Fig. S2). Fig. 1 shows the catalytic activities for ozone decomposition over OMS-2 and M-OMS-2 catalysts when relative humidity (RH) was $45 \%$. The 


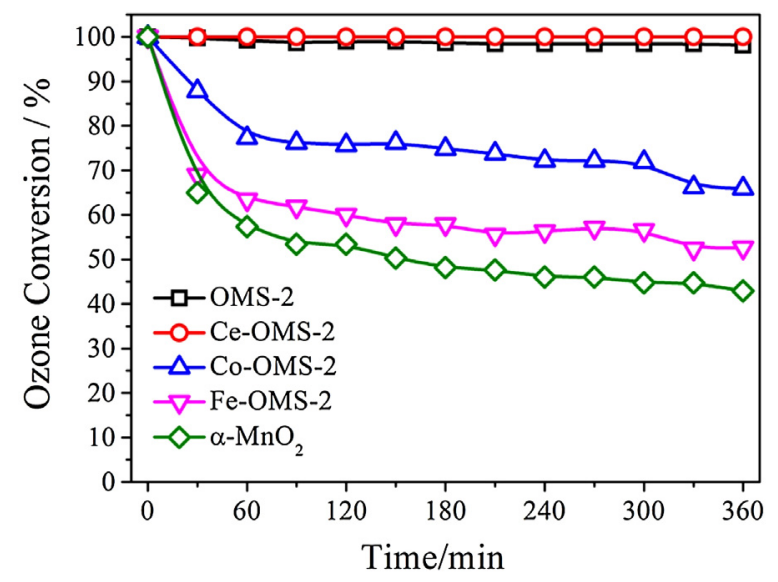

Fig. 1. The conversion of ozone on the OMS-2, M-OMS-2 and $\alpha-\mathrm{MnO}_{2}$ catalysts at $\mathrm{RH}=45 \%$.

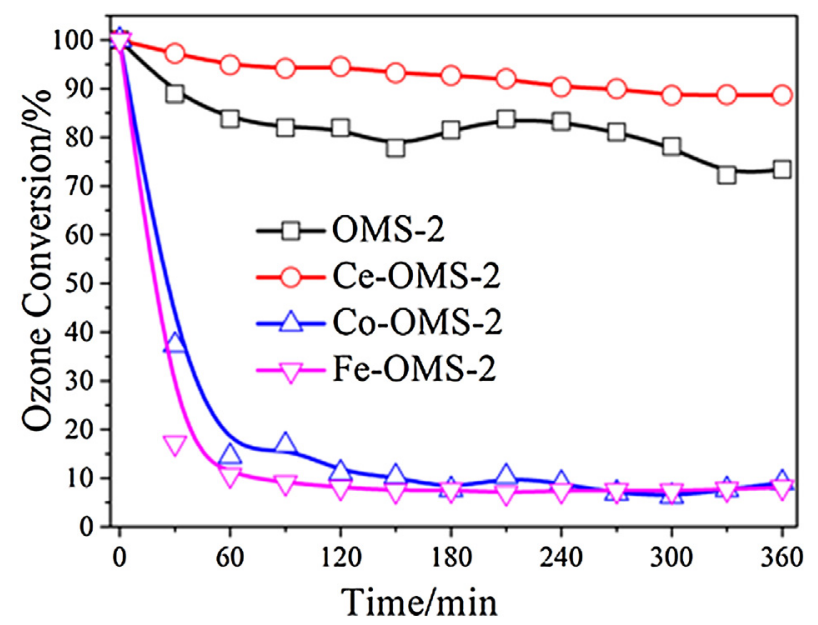

Fig. 2. The conversion of ozone on the OMS- 2 and M-OMS-2 catalysts at $\mathrm{RH}=90 \%$.

activities of OMS-2 and Ce-OMS-2 were nearly $100 \%$ even after $6 \mathrm{~h}$. The Co-OMS-2 catalyst exhibited $60-70 \%$ ozone conversion. However, the Fe-OMS-2 material was by far the least active, with a conversion percentage of only $50 \%$ after $6 \mathrm{~h}$. These results indicate that the addition of transition metals has a great influence on the activity. A well-known $\alpha-\mathrm{MnO}_{2}$ catalyst only exhibited $\sim 40 \%$ ozone conversion.

Water vapor, which could compete with ozone for adsorption on the catalyst, had a great impact on the ozone conversion and led to a decrease in catalytic activity. Compared with the OMS-2 catalyst, the Ce-OMS-2 material maintained better ozone conversion performance ( $\sim 90 \%$ ) under high relative humidity (Fig. 2 ), the activity of Co-OMS-2 and Fe-OMS-2 decreased significantly under high humidity conditions.

\subsection{The crystal structure of the catalysts}

XRD was used to confirm the identity and phase purity of OMS-2 and M-OMS-2 samples. The XRD patterns of OMS-2 and M-OMS2 materials were in good agreement with the standard tetragonal structure of cryptomelane-type manganese oxide (JCPDS 29-1020) as shown in Fig. 3. The reflections obtained were characteristic of the $2 \times 2$ tunnel structure of regular OMS-2 [26]. No additional peaks assignable to compounds of the doped metal species appear in the materials, indicating that the doped metal species are well dispersed or incorporated into the structure. The variations in peak

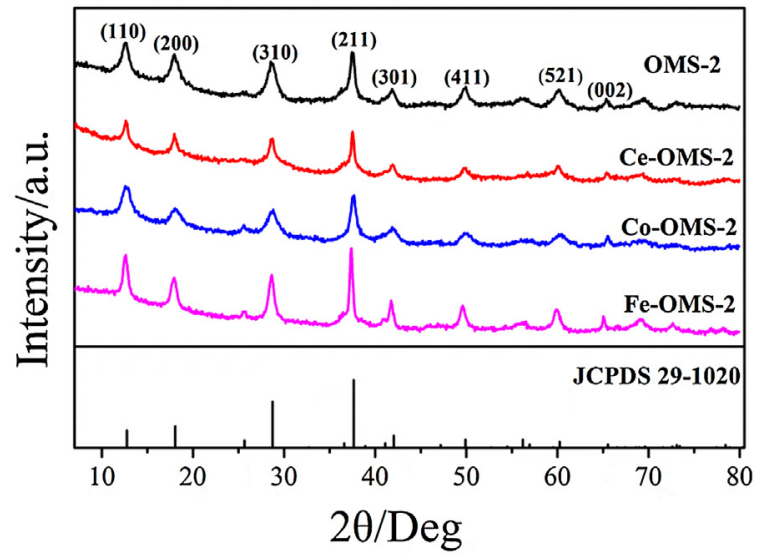

Fig. 3. XRD patterns of the OMS-2 and M-OMS-2 catalysts.

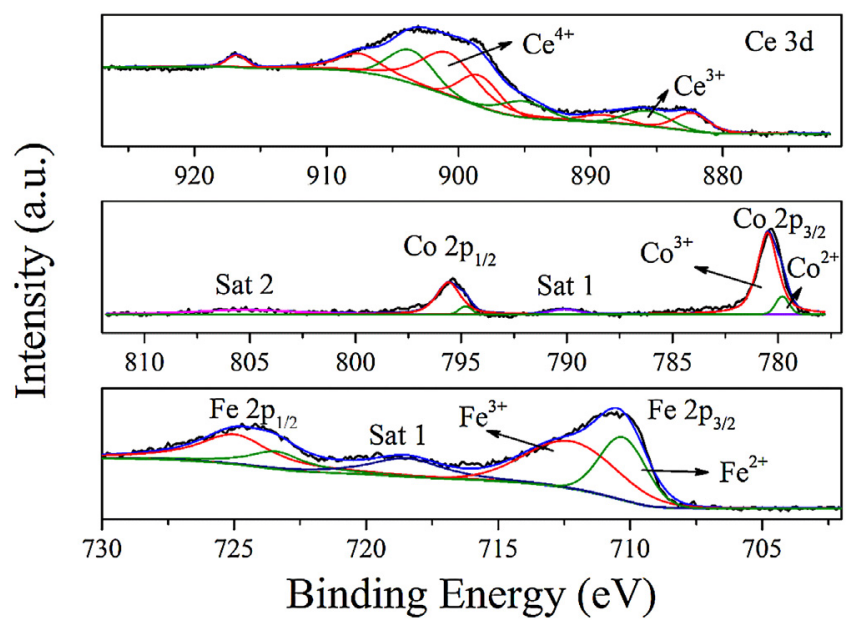

Fig. 4. XPS deconvolution spectra of Ce3d peak of Ce-OMS-2, Co 2p peak of Co-OMS2 and Fe 2p peak of Fe-OMS-2.

broadening among the synthesized catalysts revealed differences in crystallinity. The diffraction peaks of Ce-OMS-2 are broadened and decreased in intensity in comparison to the OMS-2 catalyst. However, the Fe-OMS-2 material shows narrow and high intensity peaks, and the Co-OMS-2 pattern is almost the same as that of OMS-2. The addition of Ce resulted in the formation of a poorly crystalline phase for the Ce-OMS-2 catalyst, introducing more defects and enhancing the surface area, which could favor ozone decomposition.

\subsection{The oxidation state of $\mathrm{Ce}, \mathrm{Co}$ and $\mathrm{Fe}$ in the catalysts}

As shown in the XPS results in Fig. 4, the oxidation state of Ce, $\mathrm{Co}$ and $\mathrm{Fe}$ ions in the catalysts were characterized by analyzing their Ce 3d, Co 2p and Fe 2p spectra. For Ce3d spectra, six peaks at $916.7,907.5,900.8,898.4,889$, and $882.3 \mathrm{eV}$ can be identified, which are characteristic of the $\mathrm{Ce}^{4+} 3 \mathrm{~d}$ final state (red), while four peaks at $903.6,895,885.7$, and $880.5 \mathrm{eV}$ corresponding to the $\mathrm{Ce}^{3+}$ $3 \mathrm{~d}$ final state (green) [31-33]. The atomic ratio of $\mathrm{Ce}^{3+} / \mathrm{Ce}_{\text {total }}$ was estimated from the integrated areas of these peaks to be $30 \%$, indicating most Ce ions exist in the form of $\mathrm{Ce}^{4+}$. The Co $2 \mathrm{p}$ spectrum exhibits two major peaks at $\sim 780 \mathrm{eV}$ and $\sim 795 \mathrm{eV}$ corresponding to Co $2 \mathrm{p}_{2 / 3}$ and Co $2 \mathrm{p}_{1 / 2}$, respectively. Additionally, two shake-up satellite peaks (Sat 1 and Sat 2) were observed at $790.2 \mathrm{eV}$ and $805.3 \mathrm{eV}$. By curve fitting, the obtained binding energy values were obtained as $\sim 779.8 \mathrm{eV}$ and $\sim 780.5 \mathrm{eV}$ for Co $2 \mathrm{p}_{3 / 2}$, and $\sim 794.8 \mathrm{eV}$ and $\sim 795.6 \mathrm{eV}$ for $\mathrm{Co} 2 \mathrm{p}_{1 / 2}$, which corresponds to $\mathrm{Co}^{2+}$ in tetrahedral 


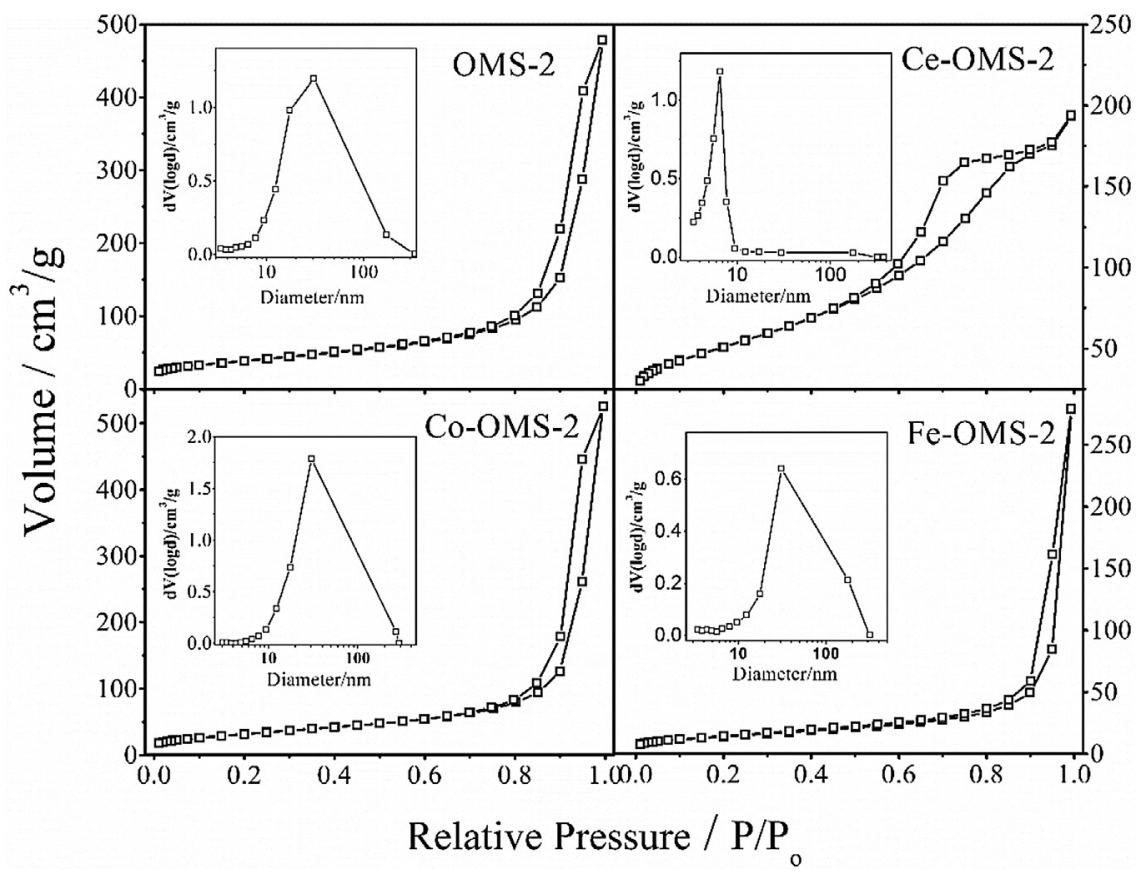

Fig. 5. $\mathrm{N}_{2}$ adsorption/desorption isotherm for OMS-2 and M-OMS-2 at $77 \mathrm{~K}$. The insert shows the pore size distribution plot calculated by the BJH method.

coordination and $\mathrm{Co}^{3+}$ in octahedral coordination in Co-OMS-2[34]. $\mathrm{Co}^{3+} / \mathrm{Co}_{\text {total }}$ is around $95 \%$, as calculated from the ratio of the integrated areas of these peaks. These results indicate that most of the Co ions were $\mathrm{Co}^{3+}$ and distributed in octahedral sites in Co-OMS-2. In the Fe $2 \mathrm{p}$ spectra, there are two major peaks, namely Fe $2 \mathrm{p}_{2 / 3}$ and Fe $2 \mathrm{p}_{1 / 2}$ at $\sim 710 \mathrm{eV}$ and $\sim 725 \mathrm{eV}$, and a satellite peak occurs at $\sim 718 \mathrm{eV}$ corresponding to the oxidation of $\mathrm{Fe}^{3+}$ and $\mathrm{Fe}^{2+}[34]$. After deconvolution, four peaks at 710.3, 712.2, 723.4, and $724.9 \mathrm{eV}$ were obtained. The peaks at 712.2 and $724.9 \mathrm{eV}$ correspond to $\mathrm{Fe}^{3+}$ and are associated with the octahedral site. The peaks at 710.3 and $723.4 \mathrm{eV}$ correspond to $\mathrm{Fe}^{2+}$ and are associated with the tetrahedral site. $\mathrm{Fe}^{2+} / \mathrm{Fe}_{\text {total }}$ is around $36 \%$, calculated by the ratio of the integrated areas of these peaks. These results indicate that most of the Fe ions were $\mathrm{Fe}^{3+}$ and distributed in octahedral sites in Fe-OMS-2.

\subsection{The effect of $\mathrm{Ce}$, Co and Fe on surface areas and morphology of the catalysts}

Fig. 5 shows $\mathrm{N}_{2}$ adsorption-desorption isotherms and corresponding Barrett-Joyner-Halenda (BJH) pore-size distribution curves for the M-OMS-2 oxides. The isotherms of OMS-2, Co-OMS-2 and Fe-OMs-2 show a characteristic type II isotherm pattern, with a hysteresis loop of type $\mathrm{H} 3$ in the IUPAC classification, which is usually associated with the adsorption on aggregates of particles with a layered morphology, forming slit-like pores [27]. The results are similar to those previously reported for OMS-2 [12,35,36].The isotherms show a characteristic type IV isotherm pattern for CeOMS-2, with a hysteresis loop of type $\mathrm{H} 2$ in the IUPAC classification. At low $\mathrm{P} / \mathrm{P}_{0}$, the curves for the Ce-OMS-2 material had relatively higher slopes than for the other materials, further indicating its relatively high surface area and lowered degree of crystallinity. This is in agreement with the XRD data. Compared with other M-OMS-2 materials, Ce-OMS-2 shows a relatively narrow pore size distribution, with an average pore diameter of $6.36 \mathrm{~nm}$, and these results are consistent with the FESEM data. The surface areas of OMS-2, CeOMS-2, Co-OMS-2 and Fe-OMS-2 were 137, 200, 115 and $52 \mathrm{~m}^{2} / \mathrm{g}$, respectively. The surface area of Ce-OMS-2 is two times higher than that of OMS-2, probably a main factor in the better performance of Ce-OMS-2 material. However, combined with previous research results [15], the surface area is not the key reason for the differences in apparent activity of the catalysts.

The morphology of as-prepared catalysts was characterized by FESEM and the images are shown in Fig. 6. The OMS- 2 catalyst displays the typical fibrous morphology with a length from 100 to $150 \mathrm{~nm}$ and a diameter of about $10 \mathrm{~nm}$. The addition of Co has little effect on the morphology of the Co-OMS-2 catalyst. However, the Fe-OMS-2 system shows a chunky microstructure. The average length of the particles was reduced from $\sim 100-150 \mathrm{~nm}$ to $\sim 50 \mathrm{~nm}$. Another notable feature is the expansion of the average width of the particles from $\sim 10 \mathrm{~nm}$ in OMS-2 to $\sim 20 \mathrm{~nm}$ in Fe-OMS- 2 . The morphology of Ce-OMS-2, which has a honeycomb structure, is markedly different from the other M-OMS-2 catalysts. The morphology of the catalysts were confirmed by the TEM (Fig. S3). The formation of this morphology was most likely due to a slight distortion of the tetragonal crystal structure from tetragonal (space group $I 4 / \mathrm{m}$ ) to monoclinic geometry (space group $I 2 / \mathrm{m}$ ) [26]. This type of morphology can lead to a large number of adsorption sites in the materials and thus improve the catalytic performance for ozone decomposition. The differences in the morphology may be attributed to the final state of metal species. Since only a single phase could be observed in the XRD results, the possibility of having another metal oxide phase could be ruled out. Another possibility could be that metal species may be inserted into the structure of the M-OMS-2 catalysts during the nucleation and growth processes. During the hydrothermal synthesis process, the additional ions either occupy sites in the framework to replace $\mathrm{Mn}^{3+}$ and $\mathrm{Mn}^{4+}$ or in the tunnel sites to replace $\mathrm{K}^{+}$.

\subsection{The position of $\mathrm{Ce}, \mathrm{Co}$ and $\mathrm{Fe}$ in the structure and role on ozone decomposition}

In order to confirm the position of the added metals in the structure, the bulk contents of $\mathrm{K}, \mathrm{Mn}$ and the added metal for all the catalysts were determined by ICP-OES. Although the initial weight contents of dopant metal cations in the reactants were the same in the syntheses of different M-OMS-2materials, the final doped M contents in the prepared materials were different from each other. This is probably because different metal cation dopants have dif- 


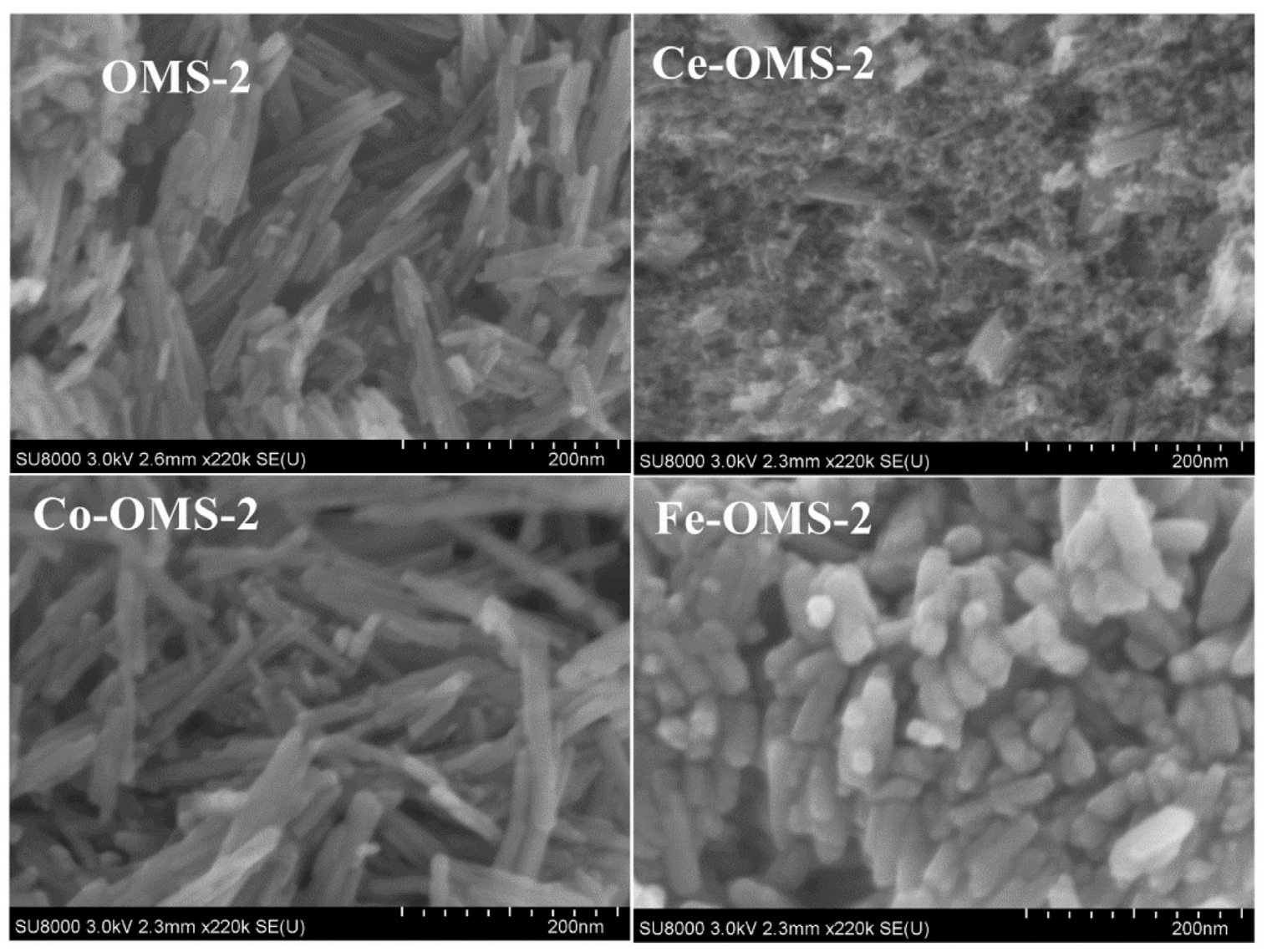

Fig. 6. FESEM images of the OMS-2 and M-OMS-2 catalysts.

Table 1

The contents of K, Mn and added metals determined by ICP-OES.

\begin{tabular}{llll}
\hline Catalysts & $\mathrm{K} / \mathrm{Mn}+\mathrm{M}+\mathrm{K}(\%)$ & $\mathrm{M} / \mathrm{Mn}+\mathrm{M}+\mathrm{K}(\%)$ & $\mathrm{Mn} / \mathrm{Mn}+\mathrm{M}+\mathrm{K}(\%)$ \\
\hline OMS-2 & 6.37 & $\backslash$ & 93.63 \\
Ce-OMS-2 & 4.82 & 8.47 & 86.71 \\
Co-OMS-2 & 6.40 & 8.45 & 85.15 \\
Fe-OMS-2 & 6.31 & 10.05 & 83.64 \\
\hline
\end{tabular}

ferent physical and chemical properties that affect the substitution of cations into the OMS-2 structure during synthesis. As shown in Table 1 , the bulk K/Mn $+\mathrm{M}+\mathrm{K}$ mass ratio $(6.40 \%)$ of Co-OMS-2 and the mass ratio (6.31\%) of Fe-OMS-2 were almost the same as the $\mathrm{K} / \mathrm{Mn}+\mathrm{M}+\mathrm{K}$ actual ratio (6.37\%) of the pure OMS-2 catalyst. At the same time, the bulk $\mathrm{Mn} / \mathrm{Mn}+\mathrm{M}+\mathrm{K}$ mass ratios of Co-OMS-2 and Fe-OMS-2 were both lower than that of the OMS-2 material. These results confirmed that the $\mathrm{Co}^{3+}$ and $\mathrm{Fe}^{3+}$ species may compete with $\mathrm{Mn}^{3+}$ and occupy a site in the framework of the M-OMS-2 material. For the Ce-OMS-2 material, the concentrations of $\mathrm{K}$ ions and Mn ions were all lower than those in the OMS-2 material, which means that the substitution of both $\mathrm{Mn}$ ions in the framework and $\mathrm{K}^{+}$in the tunnel sites of OMS- 2 by the added cerium took place. This is also supported by the fact that the $\mathrm{Mn} / \mathrm{Mn}+\mathrm{M}+\mathrm{K}$ mass ratios in Ce-OMS-2 materials were higher than those in Co-OMS-2 materials. These results were confirmed by the subsequent XAFS data.

In the OMS-2 structure, the potassium cations occupy a special position (000) in the unit cell of cryptomelane and support the tunneled framework. If the smaller $\mathrm{Ce}^{3+}$ ions $(1.14 \mathrm{~A})$ or $\mathrm{Ce}^{4+}$ ions $(0.87 \mathrm{~A})$ substituted for the $\mathrm{K}^{+}$ions $(1.65 \mathrm{~A})$, the tunnel may be distorted $[37,38]$. Genuino et al. point out that the ideal tetragonal unit cell can undergo a small structural distortion that lowers the symmetry to the monoclinic space group $I 2 / \mathrm{m}$ when large cations substitute for octahedral $\mathrm{Mn}^{4+}$ and $\mathrm{Mn}^{3+}$ in OMS-2 [26]. The special morphology of the Ce-OMS-2 catalyst was most likely due to this type of slight distortion of the unit cell. Considering the crystal radii of $\mathrm{Co}^{2+}(0.79 \AA), \mathrm{Co}^{3+}(0.685 \AA), \mathrm{Fe}^{2+}$ (high spin, $0.78 \AA$; low spin, $0.61 \AA)$, and $\mathrm{Fe}^{3+}(0.785 \AA)$, which are significantly lower than that of $\mathrm{K}^{+}(1.65 \AA)$, it is difficult for Co and Fe species to substitute for $\mathrm{K}$ ions $[11,24,39]$. Because the crystal radius of $\mathrm{Fe}^{3+}(0.785 \AA)$ is similar to $\mathrm{Mn}^{4+}\left(0.67 \AA\right.$ ) and $\mathrm{Mn}^{3+}$ (high spin, $0.785 \AA$; low spin, $0.72 \AA$ ) [25], when Fe enters the octahedral framework of the OMS2 material, it may cause the observed different particle growth behavior, the morphology of Fe-OMS-2 changed from nanoneedles to nanorods with Fe doping [24]. Considering the crystal radius of $\mathrm{Co}^{3+}(0.685 \AA)$, which is very close to that of $\mathrm{Mn}^{4+}$, Co species may reside in the framework sites and form $\mathrm{CoO}_{6}$ units, and the morphology of Co-OMS-2 was almost the same as that of the OMS-2 catalyst [11].

X-ray absorption fine structure (XAFS), including X-ray absorption near edge structure(XANES) and extended X-ray absorption fine structure (EXAFS), was used to determine the electronic and structural properties of the catalysts. The EXAFS study of $\mathrm{MnO}_{2}$ is fairly straightforward since it has only one kind of Mn site. XAFS spectra of the Mn-K edge, including XANES and EXAFS, were measured using $\mathrm{Mn}$ foil, $\mathrm{MnO}, \mathrm{Mn}_{2} \mathrm{O}_{3}$ and $\mathrm{MnO}_{2}$ as reference samples. As shown in Fig. 7A, the XANES spectra of $\mathrm{MnO}_{2}$ and $\mathrm{Mn}_{2} \mathrm{O}_{3}$ were similar and both the pre-edge peaks and the post-edge regions of Mn-K XANES in OMS-2 catalysts were similar to those spectra. Yet, no obvious differences between OMS-2 and M-OMS-2 were observed. Afterwards, to further determine the average valence of Mn species in our catalysts, the first-order derivatives of Mn-K XANES in the series of $\mathrm{MnO}_{x}$ catalysts were taken and compared with those in the reference samples. As shown in Fig. 7B, the 

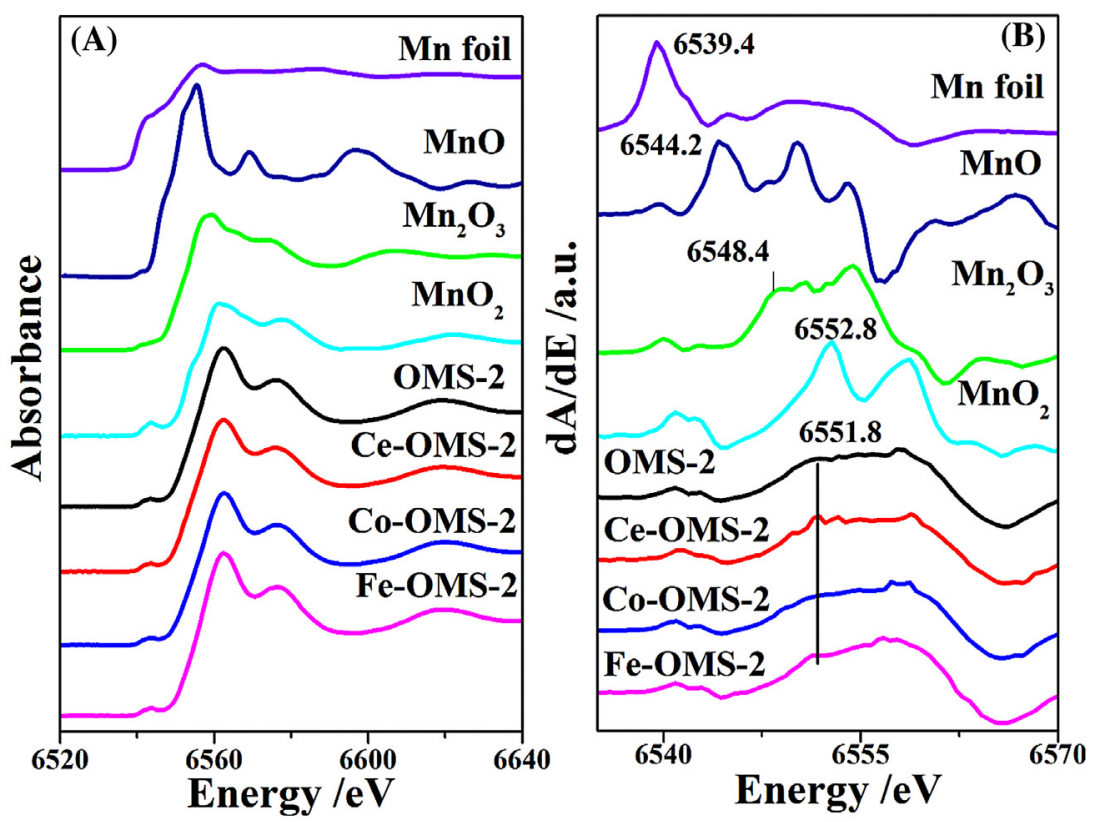

Fig. 7. (A) XANES and (B) first-order derivatives of XANES of MnK-edge in series of MnOx catalysts and Mn-containing reference samples.

Mn K-edge absorption energy $\left(\mathrm{E}_{0}\right)$ of the reference materials was determined to be 6548.4 and $6552.8 \mathrm{eV}$ for $\mathrm{Mn}_{2} \mathrm{O}_{3}$ and $\mathrm{MnO}_{2}$, respectively. The absorption edge energy of $\mathrm{Mn}$ species in OMS2 and M-OMS- 2 catalysts was $6551.8 \mathrm{eV}$, which was slightly less than that in $\mathrm{MnO}_{2}$, most probably due to the presence of a small amount of $\mathrm{Mn}^{3+}$. The exact amount of $\mathrm{Mn}^{3+}$ in OMS-2 catalysts calculated by the Rex2000 software was $14.4 \%, 23.7 \%, 4.08 \%$ and $0 \%$ for OMS-2, Ce-OMS-2, Co-OMS- 2 and Fe-OMS-2, respectively. These results verified that $\mathrm{Co}^{3+}$ and $\mathrm{Fe}^{3+}$ replace $\mathrm{Mn}^{3+}$ and $\mathrm{Ce}^{4+}$ replaces $\mathrm{Mn}^{4+}$ in the cryptomelane structure. Linear combination fitting of the XANES spectra of the OMS-2 catalysts with Mn foil, $\mathrm{MnO}, \mathrm{Mn}_{2} \mathrm{O}_{3}$ and $\mathrm{MnO}_{2}$ reference materials showed that the percentage of $\mathrm{Mn}_{2} \mathrm{O}_{3}$ in the catalysts was $7.2,11.85,2.04 \%$ and $0 \%$, respectively. These results indicate that the electronic and local structure of our $\mathrm{MnO}_{x}$ catalysts is similar to that of $\mathrm{MnO}_{2}$, which is in good accordance with the XRD results. The content of $\mathrm{Mn}^{3+}$ was consistent with the activity of the catalysts, which indicates that the high $\mathrm{Mn}^{3+}$ content is favorable for the catalytic decomposition of ozone. The average oxidation state (AOS) of Mn was estimated base on the following formula: $A O S=8.956-1.126 \Delta \mathrm{Es}$ $(\mathrm{eV})$, where $\Delta \mathrm{Es}$ is the binding energy difference between the doublet Mn 3 s peaks as shown in Fig. S4 [40]. The results (Table S1) show that the AOS decrease in the order of Fe-OMS-2>Co-OMS$2>$ OMS-2 $>$ Ce-OMS-2, which is consistent with the XANES data mentioned above.

Fig. 8A shows the filtered $k^{3}$-weighted EXAFS oscillations Fourier transformed into $\mathrm{R}$ space of the MnK-edge in the series of OMS-2 and M-OMS-2 catalysts, and Fig. 8B shows the correspond-
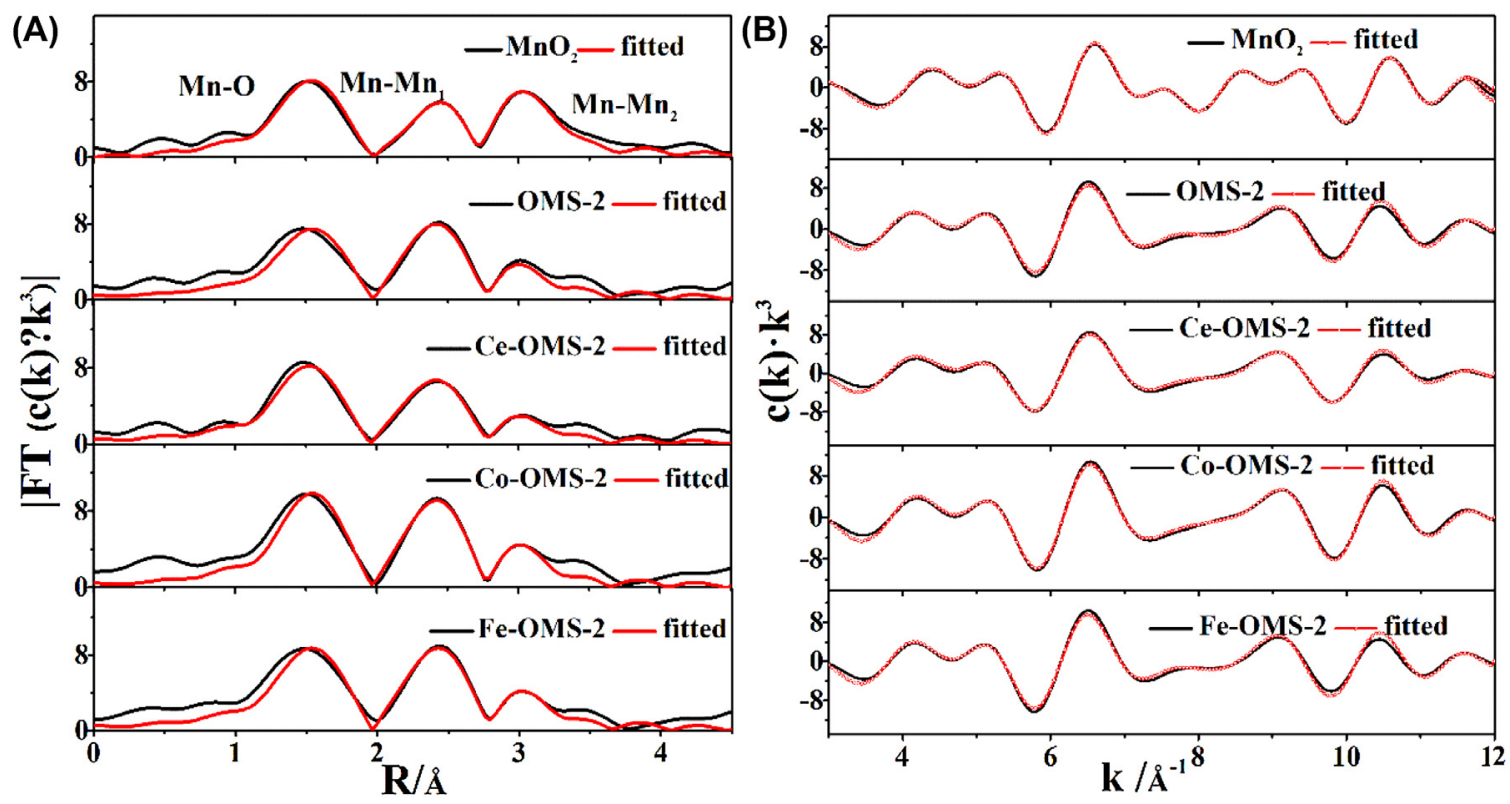

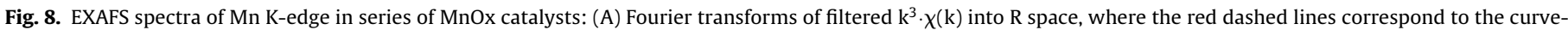

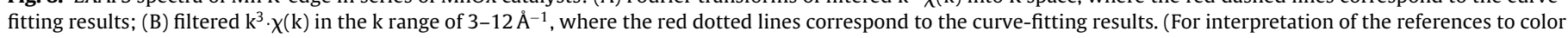
in this figure legend, the reader is referred to the web version of this article.) 
Table 2

Curve-fitting results of Mn K-edge EXAFS in OMS-2 and M-OMS-2 catalysts.

\begin{tabular}{|c|c|c|c|c|c|c|}
\hline Sample & Mn-K Reference & Shell & $\mathrm{CN}^{\mathrm{a}}$ & $\mathrm{R}^{\mathrm{b}}(\AA)$ & $\mathrm{DW}^{\mathrm{c}}(\AA)$ & $\mathrm{R}$ factor $(\%)$ \\
\hline $\mathrm{MnO}_{2}$ & $\alpha-\mathrm{MnO}_{2}$ & $\mathrm{Mn}-\mathrm{OMn}-\mathrm{Mn}_{1} \mathrm{Mn}-\mathrm{Mn}_{2}$ & 5.94 .04 .0 & 1.912 .863 .44 & 0.0630 .0820 .032 & 0.3 \\
\hline OMS-2 & $\alpha-\mathrm{MnO}_{2}$ & $\mathrm{Mn}-\mathrm{OMn}-\mathrm{Mn}_{1} \mathrm{Mn}-\mathrm{Mn}_{2}$ & 5.64 .02 .6 & 1.922 .873 .40 & 0.0600 .0570 .050 & 2.0 \\
\hline Ce-OMS-2 & $\alpha-\mathrm{MnO}_{2}$ & $\mathrm{Mn}-\mathrm{OMn}-\mathrm{Mn}_{1} \mathrm{Mn}-\mathrm{Mn}_{2}$ & 5.63 .81 .9 & 1.912 .863 .44 & 0.0560 .0660 .051 & 1.9 \\
\hline Co-OMS-2 & $\alpha-\mathrm{MnO}_{2}$ & $\mathrm{Mn}-\mathrm{OMn}-\mathrm{Mn}_{1} \mathrm{Mn}-\mathrm{Mn}_{2}$ & 6.44.43.6 & 1.922 .863 .43 & 0.0510 .0560 .066 & 1.0 \\
\hline Fe-OMS-2 & $\alpha-\mathrm{MnO}_{2}$ & $\mathrm{Mn}-\mathrm{OMn}-\mathrm{Mn}_{1} \mathrm{Mn}-\mathrm{Mn}_{2}$ & 6.44.23.6 & 1.922 .873 .43 & 0.0600 .0550 .067 & 1.9 \\
\hline
\end{tabular}

a $\mathrm{CN}$ : coordination number.

b R: bond distance.

c DW: Debye-Waller factor.

ing filtered $k^{3} \cdot \chi(k)$ in the $k$ range of $3-12 \AA^{-1}$. It should be noted that the EXAFS data for the OMS- 2 catalysts was modeled based on the structure of $\mathrm{MnO}_{2}$, and no contribution from $\mathrm{Mn}_{2} \mathrm{O}_{3}$ was considered in the fitting of these catalysts. Because of the fact that the highest proportion of $\mathrm{MnO}_{x}$ in the form of $\mathrm{Mn}_{2} \mathrm{O}_{3}$ in our OMS2 and M-OMS-2 catalysts is only $11.85 \%$, this fitting is reasonable [41]. The single and multiple scattering paths from the tetragonal cryptomelane structure(space group $\mathrm{I} / \mathrm{m} / \mathrm{m}$ ) of $\alpha-\mathrm{MnO}_{2}$ were used as the reference model. The crystal structure of the reference material is listed in Table S2. As also shown in Fig. 7A, due to the residual potassium species in the catalysts, the coordination shells of $\mathrm{Mn}-\mathrm{O}$ and $\mathrm{Mn}-\mathrm{Mn}$ in our catalysts were different to a certain extent when compared with those in the $\mathrm{MnO}_{2}$ standard samples (e.g. the relative peak intensities of $M n-M_{1}$ and $M n-M_{2}$ ). These potassium ions occupied the interstitial sites formed by the stacking of $\mathrm{Mn}-\mathrm{O}$ octahedrons [42]. From Fig. 8B, we can see that good curve fitting degrees could be obtained between experimental data and theoretical results, and the curve-fitted data are presented in Table 2.

After curve fitting, the reference material $\left(\alpha-\mathrm{MnO}_{2}\right)$ was confirmed to possess $\mathrm{Mn}-\mathrm{O}, \mathrm{Mn}-\mathrm{Mn}_{1}$ and $\mathrm{Mn}-\mathrm{Mn}_{2}$ coordination shells at ca.1.91, 2.86 and $3.44 \AA$ with the coordination numbers being 5.9, 4.0 and 4.0, respectively. Moreover, it is clear that not only the first coordination shell of $\mathrm{Mn}-\mathrm{O}$ but also the second coordination shells of $\mathrm{Mn}-\mathrm{Mn}_{1}$ plus $\mathrm{Mn}-\mathrm{Mn}_{2}$ in OMS-2 and M-OMS-2 are almost the same as those in the $\mathrm{MnO}_{2}$ reference sample. However, the OMS-2 andCe-OMS-2 catalysts showed a relatively small coordination number for the $\mathrm{Mn}-\mathrm{Mn}_{2}$ coordination shell, suggesting that these catalysts possessed more abundant surface defects [43].The Ce-OMS-2 catalyst has the lowest coordination number for the $\mathrm{Mn}-\mathrm{Mn}_{2}$ coordination shell and the best ozone decomposition performance. The coordination number for the $\mathrm{Mn}-\mathrm{Mn}_{2}$ shell of the Co-OMS-2 and Fe-OMS-2 catalysts is higher than that of OMS2 , corresponding to the lower activity for ozone decomposition. These results suggest that the surface defects were beneficial to the adsorption and activation of ozone.

Jia et al. [40] found that the catalytic activity of $\mathrm{MnO}_{2}$ strongly depended on the density of oxygen vacancies. As we know, more $\mathrm{Mn}^{3+}$ in the manganese dioxide means more oxygen vacancies will be generated. Surface species can be distinguished by the $01 \mathrm{~s} \mathrm{spec-}$ tra (Fig. 9). The asymmetrical 01s spectra could be deconvoluted to two peaks. The main peak at a binding energy of 529.7 can be assigned to the lattice oxygen $\left(\mathrm{O}^{2-}\right)$ (denoted as $\mathrm{O}_{\text {latt }}$ ), and the signal at a binding energy of 531.5 corresponded to the surface adsorbed oxygen with low coordination (denoted as $\mathrm{O}_{\text {sur }}$ ). The $\mathrm{O}_{\text {sur }} / \mathrm{O}_{\text {latt }}$ molar ratio decrease in sequence of Ce-OMS-2 (0.61) $>$ OMS-2 $(0.49)>$ Co-OMS-2 (0.43) Fe-OMS-2 (0.44). This results indicates that Ce-OMS-2 has the most abundant surface adsorbed oxygen, which is consistent with its highest amount of $\mathrm{Mn}^{3+}$ (XANES data), because usually oxygen molecules are adsorbed at the oxygen vacancies of an oxide material. Therefore, the highest activity of Ce-OMS-2 toward ozone decomposition is ascribed to its highest surface defect (surface oxygen vacancies).

$\mathrm{H}_{2}$-TPR experiments were performed to investigate the reducibility of the catalysts. The final reduction of $\mathrm{MnO}_{2}$ could be

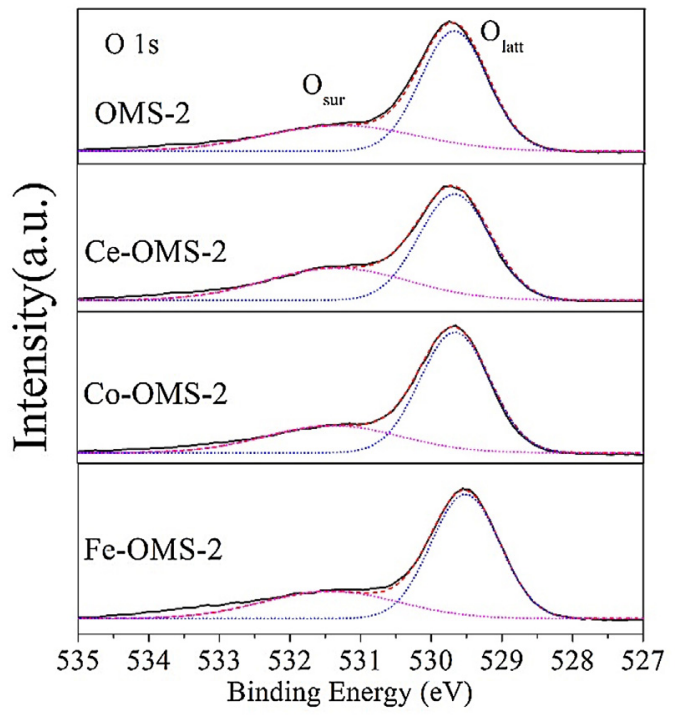

Fig. 9. O1s XPS spectra of OMS-2 and M-OMS-2.

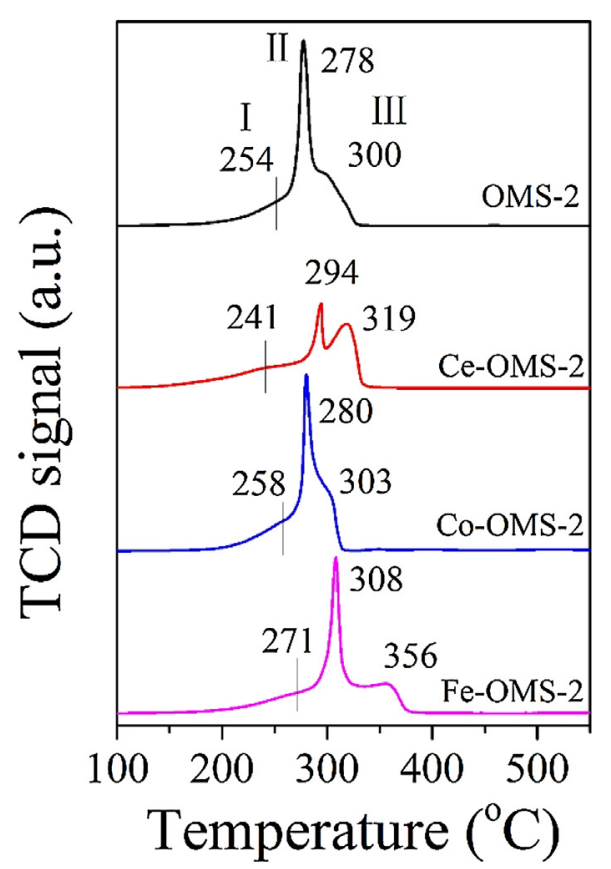

Fig. 10. TPR profiles of the OMS-2 and M-OMS-2 catalysts.

MnO with $\mathrm{Mn}_{2} \mathrm{O}_{3}$ and $\mathrm{Mn}_{3} \mathrm{O}_{4}$ as intermediates [44]. Three principal peaks (peak I-III) were assumed from the TPR analysis (Fig. 10). For OMS-2, Co-OMS-2 and Fe-OMS-2, the ratio of peak II to peak III is about 2:1, which is a typical feature of the reduction of $\mathrm{MnO}_{2}$, consistent with conversion of $\mathrm{MnO}_{2}$ to $\mathrm{Mn}_{3} \mathrm{O}_{4}$, and then $\mathrm{Mn}_{3} \mathrm{O}_{4}$ to 
MnO [45]. For Ce-OMS-2, the ratio of peak II to peak III is about $1: 1$, which indicate the existence of a different reduction route, that is $\mathrm{MnO}_{2}$ to $\mathrm{Mn}_{2} \mathrm{O}_{3}$ and then to $\mathrm{MnO}$. Peak I corresponding to the consumption of structural oxygen close to the surface, without decomposition of the material. The reducibility of the catalyst decrease in sequence of Ce-OMS-2 (241) > OMS-2 (254) Co-OMS2 (258) > Fe-OMS-2 (271). The reducibility tested by $\mathrm{H}_{2}$-TPR could reflect the oxygen mobility in the catalyst: since Ce-OMS-2 shows the reduction peak at the lowest temperature, it was proven to possess the most mobile oxygen species among the four catalysts. Consequently, the high oxygen mobility causes more oxygen to be adsorbed, which was consistent with the 01 s results and benefit for the ozone decomposition.

The mixed valency $\left(\mathrm{Mn}^{4+}\right.$ and $\left.\mathrm{Mn}^{3+}\right)$ in M-OMS-2 catalysts was important for electron transport because the efficiencies of catalysts, especially those serving as catalysts for redox reactions, are usually governed by their ability and tendency to cycle between different valence states of the relevant cationic ions [15]. Ozone decomposition on the surface of M-OMS-2 could be presented by the following reaction scheme:

$\mathrm{O}_{3}+\left[\mathrm{Mn}^{3+}\right] \rightarrow \mathrm{O}_{2}+\mathrm{O}_{\text {ads }}^{-}\left[\mathrm{Mn}^{4+}\right]$

$\mathrm{O}_{3}+\mathrm{O}_{\text {ads }}^{-}\left[\mathrm{Mn}^{4+}\right] \rightarrow 2 \mathrm{O}_{2}+\left[\mathrm{Mn}^{3+}\right]$

Abundant $\mathrm{Mn}^{3+}$ (surface oxygen vacancies) present on the surface of the catalyst could favor the ozone decomposition. Therefore, the higher content of $\mathrm{Mn}^{3+}$ contributed to the high decomposition of ozone on Ce-OMS-2.

\section{Conclusion}

Transition metal (Cerium, Cobalt, Iron) doped cryptomelanetype manganese oxides (M-OMS-2) have been successfully synthesized by reaction between metal ions, $\mathrm{Mn}^{2+}$ and potassium permanganate via a one-step hydrothermal method. Different metal-ion-doped K-OMS-2 catalysts showed distinct differences in their ozone decomposition activity. Ce was found to be beneficial to the activity, but Co and Fe were detrimental to the activity of OMS- 2 catalysts. The XRD, TGA, and XPS data suggested that the as-synthesized M-OMS-2 materials were crystalline with no segregated metal oxide impurities. ICP-OES and XAFS results confirmed that $\mathrm{Co}^{3+}$ and $\mathrm{Fe}^{3+}$ replace the $\mathrm{Mn}^{3+}$ in the cryptomelane structure and $\mathrm{Ce}^{4+}$ mainly replaces the $\mathrm{K}^{+}$in the tunnel and partially replaces the $\mathrm{Mn}^{4+}$ in the framework of the cryptomelane structure. Because of the differences in the substitution sites and the ionic radii, the morphology and the content of $\mathrm{Mn}^{3+}$ and surface defects of the catalysts were different. The content of $\mathrm{Mn}^{3+}$ and surface defects play a key role during the decomposition of ozone. Ce-OMS-2 catalysts showed a conversion of $90 \%$ under $\mathrm{RH}=90 \%$ and space velocity of $600,000 \mathrm{~h}^{-1}$, and have potential for use in decomposition of ozone under high-humidity conditions.

\section{Acknowledgments}

This work was supported by the Strategic Priority Research Program of the Chinese Academy of Sciences (XDB05050600), the Major State Research Development Program of China (2016YFC0207104) and the National Natural Science Foundation of China (51221892)

\section{Appendix A. Supplementary data}

Supplementary data associated with this article can be found, in the online version, at http://dx.doi.org/10.1016/j.apcatb.2016. 08.050.

\section{References}

[1] V. Yargeau, C. Leclair, Ozone Sci. Eng. 30 (2008) 175-188.

[2] U. Roland, F. Holzer, F.D. Kopinke, Appl. Catal. B 58 (2005) 217-226.

[3] M.A. Khadre, A.E. Yousef, J.G. Kim, J. Food Sci. 66 (2001) 1242-1252.

[4] J.I. Levy, T.J. Carrothers, J.T. Tuomisto, J.K. Hammitt, J.S. Evans, Environ. Health Perspect. 109 (2001) 1215-1226.

[5] C.J. Weschler, Indoor Air 10 (2000) 269-288.

[6] B. Dhandapani, S.T. Oyama, Appl. Catal. B 11 (1997) 129-166

[7] I. Spasova, P. Nikolov, D. Mehandjiev, Ozone Sci. Eng. 29 (2007) 41-45.

[8] M.C. Wu, N.A. Kelly, Appl. Catal. B 18 (1998) 93-104.

[9] A. Naydenov, P. Konova, P. Nikolov, F. Klingstedt, N. Kumar, D. Kovacheva, P. Stefanov, R. Stoyanova, D. Mehandjiev, Catal. Today 137 (2008) 471-474.

[10] Q.W. Yu, M. Zhao, Z.M. Liu, X.Y. Zhang, L.M. Zheng, Y.Q. Chen, M.C. Gong, Chin. J. Catal. 30 (2009) 1-3.

[11] L.R. Pahalagedara, S. Dharmarathna, C.K. King'ondu, M.N. Pahalagedara, Y.T. Meng, C.H. Kuo, S.L. Suib, J. Phys. Chem. C 118 (2014) $20363-20373$.

[12] J. Liu, Y.C. Son, J. Cai, X.F. Shen, S.L. Suib, M. Aindow, Chem. Mater. 16 (2004) $276-285$.

[13] J. Luo, Q. Zhang, J. Garcia-Martinez, S.L. Suib, J. Am. Chem. Soc. 130 (2008) 3198-3207.

[14] H. Huang, S. Sithambaram, C.-H. Chen, C. King'ondu Kithongo, L. Xu, A. Iyer, H.F. Garces, S.L. Suib, Chem. Mater. 22 (2010) 3664-3669.

[15] C. Wang, J. Ma, F. Liu, H. He, R. Zhang, J. Phys. Chem. C 119 (2015) 23119-23126.

[16] B.X. Hu, C.H. Chen, S.J. Frueh, L. Jin, R. Joesten, S.L. Suib, J. Phys. Chem. C 114 (2010) 9835-9844

[17] X. Chen, Y.F. Shen, S.L. Suib, C.L. O'Young, Chem. Mater. 14 (2002) 940-948.

[18] R.H. Wang, J.H. Li, Catal. Lett. 131 (2009) 500-505.

[19] W.Y. Hernandez, M.A. Centeno, F. Romero-Sarria, S. Ivanova, M. Montes, J.A. Odriozola, Catal. Today 157 (2010) 160-165.

[20] X. Tang, Y. Li, J. Chen, Y. Xu, W. Shen, Micropor. Mesopor. Mater. 103 (2007) $250-256$.

[21] J. Cai, J. Liu, W.S. Willis, S.L. Suib, Chem. Mater. 13 (2001) 2413-2422.

[22] R.N. Deguzman, Y.F. Shen, E.J. Neth, S.L. Suib, C.L. Oyoung, S. Levine, J.M. Newsam, Chem. Mater. 6 (1994) 815-821.

[23] G.G. Xia, Y.G. Yin, W.S. Willis, J.Y. Wang, S.L. Suib, J. Catal. 185 (1999) 91-105.

[24] X.F. Shen, A.M. Morey, J. Liu, Y.S. Ding, J. Cai, J. Durand, Q. Wang, W. Wen, W.A. Hines, J.C. Hanson, J.M. Bai, A.I. Frenkel, W. Reiff, M. Aindow, S.L. Suib, J. Phys. Chem. C 115 (2011) 21610-21619.

[25] C. Calvert, R. Joesten, K. Ngala, J. Villegas, A. Morey, X.F. Shen, S.L. Suib, Chem. Mater. 20 (2008) 6382-6388

[26] H.C. Genuino, M.S. Seraji, Y.T. Meng, D. Valencia, S.L. Suib, Appl. Catal. B 163 (2015) 361-369

[27] M. Sun, L. Yu, F. Ye, G.Q. Diao, Q. Yu, Z.F. Hao, Y.Y. Zheng, L.X. Yuan, Chem. Eng J. 220 (2013) 320-327.

[28] M. Polverejan, J.C. Viliegas, S.L. Suib, J. Am. Chem. Soc. 126 (2004) 7774-7775.

[29] P. Z, Mingxiao Wang, Jinge Li, Chuanjia Jiang, Chin. J. Catal. 35 (2014) 335-341.

[30] J. Zhang, Y. Li, L. Wang, C. Zhang, H. He, Catal. Sci. Technol. 5 (2015) 2305-2313

[31] J. Hou, Y. Li, M. Mao, X. Zhao, Y. Yue, Nanoscale 6 (2014) 15048-15058.

[32] S. Kato, M. Ammann, T. Huthwelker, C. Paun, M. Lampimaki, M.T. Lee, M. Rothensteiner, J.A. van Bokhoven, Phys. Chem. Chem. Phys. 17 (2015) 5078-5083.

[33] N.J. Lawrence, J.R. Brewer, L. Wang, T.S. Wu, J. Wells-Kingsbury, M.M. Ihrig, G. Wang, Y.L. Soo, W.N. Mei, C.L. Cheung, Nano Lett. 11 (2011) 2666-2671.

[34] R. Tholkappiyan, K. Vishista, Appl. Surf. Sci. 351 (2015) 1016-1024.

[35] J.C. Villegas, L.J. Garces, S. Gomez, J.P. Durand, S.L. Suib, Chem. Mater. 17 (2005) 1910-1918

[36] Y.S. Ding, X.F. Shen, S. Sithambaram, S. Gomez, R. Kumar, V.M.B. Crisostomo, S.L. Suib, M. Aindow, Chem. Mater. 17 (2005) 5382-5389.

[37] N. Guo, Y.H. Song, H.P. You, G.A. Jia, M. Yang, K. Liu, Y.H. Zheng, Y.J. Huang, H.J Zhang, Eur. J. Inorg. Chem. 2010 (2010) 4636-4642.

[38] T.F. Yi, J.Z. Wu, M. Li, Y.R. Zhu, Y. Xie, R.S. Zhu, RSC Adv. 5 (2015) 37367-37376.

[39] P.F. Poudeu, N. Takas, C. Anglin, J. Eastwood, A. Rivera, J. Am. Chem. Soc. 132 (2010) 5751-5760.

[40] J.B. Jia, P.Y. Zhang, L. Chen, Appl. Catal. B 189 (2016) 210-218.

[41] E. Rezaei, J. Soltan, N. Chen, Appl. Catal. B 136 (2013) 239-247.

[42] Q.H. Tang, X.N. Huang, C.M. Wu, P.Z. Zhao, Y.T. Chen, Y.H. Yang, J. Mol. Catal. A 306 (2009) 48-53.

[43] F.D. Liu, W.P. Shan, Z.H. Lian, L.J. Xie, W.W. Yang, H. He, Catal. Sci. Technol. 3 (2013) 2699-2707

[44] B. Bai, J. Li, J. Hao, Appl. Catal. B 164 (2015) 241-250.

[45] Z. Qu, Y. Bu, Y. Qin, Y. Wang, Q. Fu, Appl. Catal. B 132-133 (2013) 353-362. 